Reseña

\title{
Reseña de Ciência da Informação: crítica epistemológica e historiográfica de Gustavo Saldanha. Rio de Janeiro: Instituto Brasileiro de Informação em Ciência e Tecnologia. IBICT, 2020. ISBN 978-65-89167-01-3[1]
}

Martha Sabelli ${ }^{1}$ ORCID: 0000-0002-4130-0312

${ }^{1}$ Departamento Información y Sociedad, Instituto de Información, Facultad de Información y Comunicación, Universidad de la República; profesora titular; Sistema de Investigación, Nivel 2; Uruguay; San Salvador 1944; martha.sabelli@,fic.edu.uy.

\section{Introducción}

La revisión de narrativas de navegaciones entre teorías, conceptos y perspectivas sobre la/s disciplina/s en cuestión: un arcoíris interactivo en espacios de tiempo sincrónicos y asincrónicos

Una primera lectura del libro, con motivo de la solicitud de reseña por parte de esta revista, me provocó algunas reacciones que transmití a Gustavo en las tertulias que compartimos en el Círculo Iberoamericano de Ciencia de la Información Documental (CIIBERCID), en especial el destaque de algunos textos utilizando en primer lugar el color amarillo, pasando luego al verde y hasta el rojo, este último para ilustrar sus afirmaciones. Su comentario fue bien recibido: yo estaba construyendo un arcoíris. Efectivamente era un arcoíris de sus narrativas.

He tratado de superar las debilidades de una investigadora empírica consolidada en el área de comportamiento informativo desde inicios de los años noventa e 
incipiente en investigaciones sobre el concepto información en los últimos años, lectora de una vasta y compleja literatura sobre la teoría de la Ciencia de la Información (CI) y de Comportamiento Informativo (Estudios de Usuarios / Comportamiento Informativo / Prácticas de Información) — hecho fundamental para tomar conciencia de que uno no sabe nada o casi nada - para enfocar un libro del área de la epistemología. Por tanto, espero que esta reseña pueda ser un aporte para facilitar e invitar a la lectura del libro a los lectores de Informatio léase, profesionales y académicos sin especialización en epistemología-, quienes encontrarán en los capítulos una gran riqueza y complejidad de reflexiones para debatir y difundir.

Otra debilidad que debí enfrentar es la dificultad de un texto de epistemología escrito en portugués; en este sentido, en la reseña hay textos transcriptos en portugués.

Es necesario tener en cuenta algunos datos académicos del autor y su obra, producto de 15 años de reflexión de un joven y destacado académico de Brasil, especialmente sus actividades como investigador en el marco de varias becas de apoyo a sus investigaciones entre el 2016 y 2021 y su liderazgo del Ecce Liber, que ayudan a identificar su trayectoria en los últimos años y en la actualidad.

Gustavo Saldanha es investigador titular del Instituto Brasilero de Información en Ciencia y Tecnología (IBICT), profesor adjunto de la Universidad Federal del Estado de Río de Janeiro (UNIRIO), becario de productividade 2 del CNPW (20162018; 2019-2021) y becario de Jovem Cientista do Estado da FAPERJ (2019-2021). Se desempeña como docente en programas de posgraduación en Ciencia de la Información del IBICT y en Biblioteconomía de la UNIRIO. Es líder desde 2011 del grupo de investigación Ecce Liber: Filosofía, Lenguaje y Organización de Saberes (IBICT-UNIRIO). Es miembro, desde 2019, de CIIBERCID; desde 2017, del equipo de Meditaciones en información —investigadores de la comunicación especializado del Laboratoire d'Études et de Recherches Appliquées en Sciences Sociales (Lerass) de la Université Toulouse III Paul Sabatier, Francia; desde 2008, de la Red Franco-Brasileña de Investigadores en Mediación y Usos Sociales del Conocimiento e Información (Musi Network), y, desde 2014, del Centro Internacional de Información Ética (ICIE). Es cofundador del Foro Internacional El 
Arte de la Bibliografía (2014) y del Foro de Estudios Críticos de Información (iKritika) (2013). Fue vicecoordinador de la gestión 2015-2016 del Grupo de Trabajo 1 (Histórico y aspectos epistemológicos de la Ciencia de la Información) de la Asociación Nacional de Investigación y Posgrado en Ciencias de la Información (ANCIB). Sirvió como bibliotecario en la Fundación Biblioteca Nacional (2006-2010) (FBN) y el Instituto Brasileño de Geografía y Estadística (2010-2012) (IBGE). Licenciado en Bibliotecología de la Universidad Federal de Minas Gerais (UFMG) (2006), especialización en Filosofía Medieval de la Faculdade São Bento-RJ (2010), Maestría en Ciencias de la Información por la UFMG (2008), Doctor en Ciencias de la Información por el convenio IBICT-UFRJ (2012). Llevó a cabo, con el apoyo de Capes, en el período 2017-2018, el postDoctorado en la Université Toulouse III, Toulouse, Francia (p. 251).

Antes de intentar una síntesis de las principales ideas de Saldanha en su Preámbulo (capítulo 0) y los 11 capítulos, es necesario poner énfasis en su liderazgo del Ecce Liber, ya mencionado, pues desde mi mirada contribuyen a desentrañar los antecedentes de su pensamiento actual. De allí, mi visita al sitio web de Ecceliber con la intención de indagar, a través de la producción de sus publicaciones, las perspectivas y referentes teóricos del autor en el lapso 20162020, manifestados en el libro. La mayor parte, aproximadamente dos tercios, tienen a Saldanha como único autor o coautor (3 libros, 9 capítulos de libros, 38 artículos), con una concentración en el lapso 2018-2019 (22 artículos y 4 capítulos de libros). Los títulos de las publicaciones colaboran en identificar sus principales ejes temáticos: filología bibliográfica; discurso bibliográfico; bibliografía; fuentes bibliográficas; noción de documento; pensamiento biblioteconómicoinformacional; fundamentos epistemológicos de la bibliografía; cartografía de la epistemología en CI. Parte de ellos enfocan la realidad de la/s disciplinas en el Brasil. En suma, la producción de Saldanha, difundida por el grupo Ecce Liber, es una fuente ilustrativa sobre sus pensamientos más actuales, que facilitan la interpretación de su trayectoria en relación con las disciplinas y subdisciplinas ancladas en su enfoque de la epistemología histórica.

Finalmente, el libro tiene una estructura que responde a la puesta en escena de estudios y reflexiones durante diferentes períodos del autor, enlazados y tejidos. 
Las referencias bibliográficas están al final del capítulo 11 (pp. 224-238) y hay anotaciones de interés en notas al pie de página.

Veamos qué nos dice el preámbulo.

\section{Preámbulo y cómo navegar en las narrativas del libro}

El Preámbulo (capítulo 0, pp. 26-32) sintetiza en su título la terminante y debatible afirmación del autor: La fundamentación de la inexistencia de la Ciencia de la Información.

Desde el inicio expresa la crítica sobre la mirada occidental angloamericana sobre la CI, específicamente el desconocimiento de la producción de Asia, África y de América Latina y el Caribe, e incluso del este de Europa durante el siglo XIX. Elige dos puntos de partida de su perspectiva: la tesis de Puntel Mostafa de 1985 «que desvela la construcción neoliberal del hacer bibliométrico» y la disertación de Alcenir Soares dos Reis: «Una investigación hecha entre 1983 y 1990 que deja muy clara la construcción del campo a partir de la Biblioteconomía». Y expone:

Uma trindade de hipóteses estabeleceu o percurso dessa obra ao longo de 15 anos de reflexão, desvelada pela crítica ao pretenso movimiento paradigmático do campo via classificações epistemólogicas triádica (...):

a) La Ciencia de la Información no tiene como objeto la información.

b) La Ciencia de la Información no es interdisciplinaria.

c) La Ciencia de la Información no es una ciencia del siglo XX (p. 27, traducción propia).

El camino que sigue es la búsqueda de comprovação teórico-empírica (teorías aplicadas al universo teórico y en el espacio-tiempo del campo). Para el argumento asertivo formula tres preguntas:

a) ¿Por qué negar la pluralidad semántica en un concepto reductor de la expresión social y crítica del campo (una postura aceptada desde los enfoques neutralistas, que creen en la neutralidad científica, hasta los enfoques emancipadores, que creen en la construcción social de artefactos), pluralidad como al menos 500 años de intensa producción de trabajos sobre los dilemas del libro, el documento, el texto, el discurso, el signo, el mensaje, el esquema, el conocimiento de los datos? 
b) ¿Por qué la insistencia de un discurso interdisciplinar como modus de ser del campo em sua pretensa constituição tardia, cuando la propia argumentación bajo la noción de interdisciplinariedad se constituye contra el movimiento crítico-social de la interdisciplinariedad misma, y se desarrolla contra él (dada la profunda lucha del campo por la emancipación del discurso epistemológico de Gabriel Peignot en 1802)?

c) ¿Por qué la casmurra batalla por afirmar que la disciplina tiene «sus nacimientos» en la pos segunda guerra mundial cuando, lo que sucede es un (y no el único) proceso de mutación de nomenclaturas debido a movimientos históricos en el campo (como cada década ocurre, antes y después del contexto dado, un proceso que está inacabado, inconcluso, y que se remonta, por ejemplo, a un término ya ampliamente utilizado en el campo en el siglo XIX, en la ideología del campo mismo, a saber, el término información y un horizonte también basado en el enfoque del siglo XIX, es decir, el escenario científico?

A continuación, el autor expresa la sustancia del libro:

Quinze anos após o início da redação desse texto, atravessadas estações distintas de leitura para a busca do horizonte das hipóteses apontadas, as assertivas se tornam cada vez mais claras. As diferentes indisciplinas metodológicas experimentadas no percurso 2005-2020, a saber:

a) Apresentação panorâmica,

b) Pragmática filosófica,

c) Hermenêutica,

d) Filosofia do não,

e) Epistemologia histórica,

f) Epistemologia crítica,

g) Epistemologia horizontal,

h) Organização ordinária de saberes socialmente oprimidos, apenas ampliaram as possibilidades de confirmação da trindade.

En consonancia, reafirma su concepción sobre el término $C I$ : no representa en epifanía una ciencia y mucho menos un campo científico, lo que legó un potencial retórico a la cobertura estética de grupos de investigación, formaciones de educación superior, departamentos, centros, colegios, eventos. Así pues, produce una reducción de un vasto campo con millares de páginas producidas en el siglo 
XIX sobre los dilemas de preservación y del acceso al conocimiento registrado, de continentes y contenidos, de comunidades interseccionalizadas bajo un contexto de argumentaciones y, principalmente, de la organización de la masa documental científica, a algunos aspectos que no representan, ni siquiera la amplitud de los estudios que pasan a ser llamados de «'biblioteconômico-informacionais’ —vide o uso estadunidense intensivo da expressão Library and Information Science desde então- ou apenas “informacionais"» (p. 29).

Veamos el texto en portugués de los comentarios del autor sobre la descripción de sus reflexiones a través de una década en el libro.

a) Primeiramente, com a indicação do cenário retórico por trás de tudo, a saber, o fetiche dos mitos de origem, as narrativas epistemológicas e o desenvolvimento econômico-político, já com as desdobradas análises do período 2014-2020;

b) Em segundo lugar, a epistemologia crítico-poética, espécie aberta de metodología do percurso, recuperando os aspectos do modo tecidos entre 2006 e 2011;

c) Outro passo, presente na dissertação de 2008, recupera a querela do paradigma e a miséria de seu uso;

d) Em seguida, também fruto primeiro da dissertação de mestrado de 2008, a crítica propriamente dita sobre os mitos de origem e suas narrativas, chegando ao foco da economia política da epistemologia em jogo;

e) O «expresso BH-Copenhague» retoma também a inspiração das leituras de 2005 a 2008, constituídas sob a via da epistemologia da imaginação;

f) O mesmo percurso é estruturado com a discussão sobre a história social da terminologia macroepistemológica do campo;

g) Em Nunca Fomos Interdisciplinares, desvelamos a produção do período (década de 2000), com as abordagens das pesquisas posteriores;

h) A discussão sobre a incongruência do uso da teoria paradigmática do século XX está presente também na dissertação e na publicação inaugural de 2008 na revista Informação \& Informação;

i) A Fábula da Criação sintetiza as tautologias afirmadas ao longo da pesquisa;

j) Ipásia Vive fundamenta, a partir da discussão da virada da década (2000-2010), sob as figurações do período de produção 2015-2020, a condição da linguagem como "ato" epistêmico do campo;

k) Estas Histórias procuram alguma forma de conclusão das críticas epistemológicas e historiográficas constituídas (p. 29).

3. De la epistemología crítico-poética a la epistemología de la imaginación 
Esta reseña, como expresamos al inicio, busca facilitar y motivar la lectura de los capítulos del libro, que no necesariamente ofrecen una visión de cómo fue tejiendo el autor sus abordajes epistemológicos, en especial si se quieren conocer las transformaciones o no de sus perspectivas epistémicas, pero en cambio ofrecen reflexiones que interpelan continuamente a los lectores.

Por las características de una reseña y, en especial, de este libro y su estructura, nuestra intención es poner el énfasis en las afirmaciones propias del autor (el color rojo en nuestra lectura) y mencionar muy brevemente los abundantes referentes citados (en este caso usé el color verde) sin aludir a sus textos.

\subsection{Mitos, narrativas y economía política de una episteme}

En este capítulo 1, se aborda brevemente, por un lado, las que denomina epistemologías tardías del siglo XX —enfocadas para el registro del conocimiento, su cientificidad, su politización-y, por otro, su propuesta de crítica a los mitos. Considera que la narrativa epistemológica encuentra la trama de la creación en el corazón del discurso y que el modo como se teje cada argumento establece un género curioso de historiografía, poco dedicado a la ruptura del origen, a las narrativas epistemológicas y al desarrollo político del campo. Asimismo,

el desarrollo político ganado, con los mitos y sus narrativas, una cadena de eventos sísmicos secuenciales entre los años 1950 y los días actuales (...). Del liberalismo al neoliberalismo, el salto es fabuloso en economía política de la epistemología cambia a llamarse Library and Information Science. Todo se justifica por capital en estado informacional, inclusive la propia noción de información (...), la propia noción sin contrato de trabajo de interdisciplinariedad (contra la estructura disciplinar justificada y sindical), una visión sincrónica del big bang como metáfora sumaria de donde nacen las cosas (como si nacieran de explosiones epistemicidas, de hecho, y no fuesen creaciones clarividentes de intereses económicas) (p. 34, traducción propia).

Termina diciendo: «Ese es el camino que aquí recorremos. Ecce Liber».

\subsection{Epistemología histórica e crítica-poética. A chama bachelardiana acesa como pavio}

A partir de esta parte del libro, los textos de cada capítulo merecerían reseñas específicas, pero comprometida con este trabajo emprendemos el desafío. 
El título del capítulo 2, «Epistemología histórica y crítica-poética: la llama bachelardiana se encendió como una mecha», es ilustrativo, siguiendo las metáforas de Saldanha, de su compañero de viaje Gaston Bachelard $(1974,1983)$ y su preocupación epistémica en torno a la distancia entre la metafísica propiamente dicha y obras prácticas especiales de cada desempeño científico. La necesidad de una filosofía entre, capaz de operar entre la objetividad y la subjetividad que permean la actividad científica; una epistemología de dos polos que sobreviva a través de un desarrollo dialéctico, multilateral. Trata de abordar la epistemología «como aquilo que o autor chama de 'drama' cotidiano do estudo cotidiano (Bacherlard, 1983, p. 20) ou o estudo dos becos e travessas onde o pesquisar se faz vivo e ativo».

Saldanha (pp. 36-42) expresa algunas reflexiones dialogando con textos de Bachelard, Fracelin (2000b) y Santos (1989) que apuntan a comprender la construcción del conocimiento como un proceso de recontextualización de sentidos, de verificación rigurosa de intercambios en la preocupación de reconocimiento de la información en el cotidiano.

Veamos algunas en su texto original:

Em outras palavras, trata-se de reencontrar um humanismo (e suas tragédias) aparentemente afastado dos estudos de organização do conhecimento, mas que pode ser desvelado, em nossa hipótese, a partir do estudo da longa duração de uma certa tradição pragmática - que aborda nossos objetos de estudo como práticas de sentido, poesis, construção, contextualidade (...). É este pluralismo das vizinhanças que nos permite pensar as semelhanças de família de Wittgenstein (1979), perceber a tessitura de tradições em uma história de longa duração dos estudos informacionais - o que nos parece de suma importância em uma área do conhecimento como a CI, tão atenta aos eventos paradigmáticos que aparentemente transformam a ciência, suas nomenclaturas e modos de pesquisar (p. 37).

Centrado en Bachelard (1974) y Rorty (1997) afirma: «Ainda: este pluralismo das vizinhanças é outra maneira de pensar a metáfora dos becos e travessas do campo, ou seja, para conhecer a epistemologia é preciso visitar os discursos circunvizinhos, adentrar suas argumentações e explorar seus diálogos» (p. 38).

Y finalmente habla de una de sus principales concepciones del libro: «Concebir para este viaje una epistemología de la imaginación» y de sus intenciones: 
Explicitamos, através da noção de uma epistemologia da imaginação, a condução da vida que se leva na viagem que se propõe: a apresentação do perfil do viajante e de sua bagagem. Em suma, buscamos descrever os materiais utilizados e a técnica adotada para compor a obra, explicitando ao leitor a biografia dos passos do narrador (p. 38).

Por tanto, hay una convocatoria a una epistemología de la imaginación, un modo de concebir la filosofía de la ciencia, un pensamiento que nace de sus vivencias en bibliotecas, salas de aula, gabinetes de investigación como también en otros ambientes favorables al conocimiento como cafeterías, salas de cine, mesas de café, corredores y de la propia filosofía bachelardiana. En consecuencia: una epistemología de la imaginación no impone reglas (pp. 38-39).

Volvamos a su texto original: «Apreendemos, assim, os viajantes dos séculos XV ao XIX, como outros, representantes dos grandes espíritos científicos. Ali, a metodologia científica era: a) imaginar; b) caminhar por imaginários; c) interpretar; d) narrar» (p. 39).

Con el fin de una mayor aproximación a la perspectiva del autor, citemos el siguiente texto donde resume algunas ideas o intencionalidades epistemológicas en esta etapa de su vida académica:

Esta pesquisa é uma narrativa de viagem, uma pequena caixa de cartas provocativas, ou uma história provocativa das ideias, um poema do cotidiano da CI, um relato de remotas e recentes sensibilidades, uma reunião de crônicas, uma coletânea de fábulas, um ideário, uma memória das formações discursivas, um ensaio sobre as travessias do pensamento. Uma epistemologia da imaginação é uma provocação à criatividade informacional, à cultura científica das disciplinas da informação. Desta forma, esta é uma viagem que poderia se dizer: de epistemologia, de história, de filosofia, de organização do conhecimento. Diremos, antes, da imaginação. Qual imaginação? Uma certa imaginação dos saberes: entendendo estas categorias imersas em narrativas como provocação à sensibilidade leitora; entendendo leitor como o que é passível de se sentir conhecer; entendendo conhecimento, como Bachelard (1974), como o que incomoda, como a polêmica do conhecer (p. 39).

También acude a Mills (1975) al adherirse a una idea pragmática de la investigación mundana, la investigación de los silencios/ruido de la vida diaria, la diversidad y sus similitudes familiares. $Y$ como en otras partes, aparece Wittgenstein en el texto: «Ao longo de sua vida intelectual, a o permanente deslocamento entre a universidade e as esquinas do mundo, a guerra, o vilarejo desconhecido, o lago inóspito; entre os becos e travessas onde o conhecimento se dá» (p. 40). 
La epistemología de la imaginación abarca según el autor la idea de la investigación científica incluyendo la metodología y la redacción. En este sentido, invoca a Italo Calvino (1990), específicamente tres de sus cinco propuestas para el nuevo milenio: la levedad, precisión y visibilidad [2].

\subsection{Isso nao é uma Ciência da Informação. A traição epistemológica sob provocações magrittianas}

Al inicio de la reseña comentamos la afirmación provocativa del autor, con ella titula el capítulo 3: «Esta no es una ciencia de la información» y agrega como subtítulo «La traición epistemológica bajo las provocaciones de Magrittia».

Con el fin de expresar las principales ideas presentadas, nos extendemos, como dice el autor, en «esta visita en un viaje crítico a la epistemología de la CI (...) de un viajante - narrador que aquí avanza» (p. 45).

Empecemos por su objetivo: hacer una crítica. En este sentido, en el comienzo dice:

Nuestro objetivo aquí es tejer la crítica del desarrollo lógico epistemológico de la CI, para recoger en las narrativas los fragmentos que tejiendo la tradición de la invención y un tipo discursivo con frágil sustento. Fue en la década de 1960 que tal discursividad señaló que la CI está institucionalmente establecida, cuando el mismo término 'ciencia de la información' se legitima dentro del ámbito de los estudios de organización del conocimiento - o estudios de meta-representación (p. 43, traducción propia).

A este respecto, considera a los discursos meta-científicos como conjunto simbólico de narrativas que van constituyendo y sedimentando imaginarios, entendiendo que estas voces están formuladas tácita y lentamente, mitologías de origen y mantenimiento de una cohesión comunicacional, bajo los cuales los investigadores científicos se basan para dar vida y validez a sus argumentos. De este modo, dice, nos acostumbramos a afirmar que la CI nació en el contexto de la segunda guerra mundial. Son muchas las disertaciones, trabajos, artículos y otras narrativas científicas que parten de esta formulación para darle vida al problema de su investigación, para justificarla, posicionarla y atribuirle significados.

Así pues, aporta otra visión desde la epistemología crítico poética de Bachelard y el segundo Wittgenstein, o sea, el encuentro de la imaginación con la razón, sobre 
la exploración crítica de los fragmentos que tejen este discurso, las narrativas que construyen constelaciones de mitos de origen que aseguran al investigador su lugar como científico y aseguran su problema de investigación como objeto científico (p. 44).

Por otro lado, especifica que su línea historiográfica busca viajar en una narrativa no necesariamente vinculada al discurso de la naturaleza interdisciplinaria, guardando distancia de Pinheiro (2002) y Robredo (2003).También intenta comprender la historia de la CI más allá del término ciencia de la información, como propone Ortega (2007), pero bajo otros aspectos, busca una historiografía, más allá de la teoría de la representación y el enfoque epistemológico del desarrollo científico de Thomas Kuhn. Con respecto a hablar de paradigma, expresa su preferencia por tradiciones y profundiza sobre la noción de prolongamento en la relación entre Biblioteconomía y CI.

Asimismo, considera oportuno clarificar cuál es su paso a seguir en la investigación: «¿En qué terrenos se encuentra la epistemología de la CI y cómo los fragmentos discursivos van construyendo una tradición dentro de esta arena científica?» (p. 45). En la respuesta, manifiesta su intencionalidad: trazar, a partir del estudio crítico de los discursos, las vías abiertas para el desarrollo de una tradición pragmática dentro de la epistemología informacional.

Las sensibilidades que busca provocar en este paso más largo del viaje sugerido, atraviesan las siguientes arenas:

a) el origen de la $\mathrm{CI}$ es el resultado de discursos que buscan justificar para demarcar su experiencia de nacimiento y constitución, y buscar (...) algunas narrativas que contribuyan a tejer nuestro mito fundador;

b) se ha producido, año tras año, desde la primera década del siglo XIX un cambio en las narrativas epistemológicas dentro de los estudios informacionales hacia un pensamiento más pragmático, sociológico-antropológico, que ya está fragmentado en las discusiones iniciales del área, pero se volverá cada vez más amplia y profunda en nuestro discursos contemporáneos; buscamos, por tanto, mediante el estudio de algunas definiciones en la zona, señalar estos desplazamientos;

c) la expresión / término ciencia de la información adquiere, en este cambio, los significados más diferentes. Comenzamos este viaje, como ya se presentó, desde la noción de significado como uso, la definición pragmática de filosofía del lenguaje del segundo Wittgenstein. De esta forma, también visitamos brevemente algunos usos de la expresión dentro de los discursos científicos de los estudios informativos para comprender las consecuencias prácticas que puede tener la adopción de la ciencia de la información; 
d) los usos y desuso de la expresión ciencia de la información identificarán la dificultad de justificar sistemáticamente $\mathrm{y}$, en consecuencia, de delimitar la CI y sus subáreas de investigación práctica. De esta forma, la fragilidad de la expresión discutida desde un análisis epistemológico acaba por remitir esta fragilidad a otros términos de la zona, lo que nos hace visitar rápidamente el concepto de interdisciplinariedad, que se utiliza tanto para justificar como para demarcar epistemológicamente el alcance de la exploración de los estudios informacionales (pp. 46-47, traducción propia).

A su vez, relaciona su enfoque sobre la CI y la información a la lectura de uno de los cuadros de René Magritte realizada por Michel Foucault (1988) al reflexionar sobre la posibilidad del sentido, los diferentes horizontes de interpretación que una simple imagen, una representación, puede conducir así como sus posibilidades de simulación y disfraz. En definitiva, la puesta en debate del concepto de representación, y confirma: «La CI apoyó gran parte de su filosofía bajo el paraguas de una filosofía de representación. Son tanto la tradición física como la tradición cognitiva, así como la documentalista, bibliográfica y muchas otras tradiciones, estructuralmente influenciadas por esta filosofía» (pp. 48-49).

En el cierre del capítulo se define el camino emprendido, con base en la lectura de Foucault (1988) de la obra de Magritte, tejer:

una historiografía interpretativa y crítica de las imágenes creadas a lo largo de los mitos de fundamento y desarrollo de la CI, los juegos de lenguaje que tejieron las razones epistémicas e institucionales del área, problematizando que, en diferentes momentos en que se afirmó 'esto es ciencia de la información', la propia representación de las prácticas informacionales demostró, traicionando al clasificador, como en la ironía magrittiana, que podría significar "esto no es ciencia de la información" (p. 49, traducción propia).

\subsection{Mitos de origem. As narrativas e seus fragmentos (a história que escolhemos inventar)}

En este capítulo 4, como ilustra el título, Saldanha construye su epistemología histórica en CI entre los diferentes discursos de los abordajes sobre los orígenes de las áreas de los estudios informacionales, sea los oriundos de la Biblioteconomía, o los nacidos del encuentro de la Recuperación de Información y de la Documentación, y, en especial, los referidos a su construcción del inicio de la historiografía de la CI ligado al contexto de la segunda guerra mundial. Luego de una referencia a Goffman (1975), afirma que en vez de una ciencia lo que aparece 
«es un complejo de narrativas, estructurado en una filosofía representacional, que buscará legitimar un nuevo término, ciencia de la información, para las viejas prácticas, institucionalizándolo en las organizaciones que llevaron a cabo estas últimas» (p. 51, traducción propia).

El complejo movimiento de transformación es enfocado siguiendo textos de autores brasileños, Freire (2006), Loureiro (1999), Pinheiro (1997), Robredo (2003) y, en especial, la reconocida teórica Nélida González de Gómez (2000). Asimismo, como no podía estar ausente en un trabajo académico del área en Brasil, el emblemático teórico francés Le Coadic (1997).

Después de una revisión de las visiones sobre el origen de la CI, donde también aparecen Saracevic (1996), Wersig e Nevelling (1975), Brookes (1980) y otros (pp. 54-55), sostiene que a la luz de una epistemología de la imaginación, se refleja una concepción de la ciencia que no parte de hechos emblemáticos dentro del lenguaje científico, sino de legados de un mundo ordinario, vínculos cotidianos que un día, reunidos en unos contextos, separados en otros, serán conocidos y asentados bajo el término ciencia de la información. Pensar en los orígenes de la CI a partir de remotos vestigios de la necesidad de clasificar, organizar y dar sentido a los mitos fundacionales, así como la institucionalización de estos procesos, constituye el origen de las disciplinas de información. A través de la descripción de las definiciones y su problematización, busca identificar los fragmentos de las narrativas que tejen una cierta tradición pragmática en la epistemología informacional, para luego comprender la compleja memoria institucional de la legitimación de estos términos. Es impresionante, dice, que todas estas narrativas, en general, de manera sistemática, reproduzcan una historiografía sincrónica, ocultando la vasta producción de una teoría crítica presente en el campo en la década de 1960, independientemente del nombre del campo en sí (p. 56).

\subsection{A História social e os usos de um nome. $O$ termo ciência da informação e as declarações}


El capítulo 5 presenta resultados de la tesis de maestría de Saldanha. Como toda síntesis de una rica revisión de la nomenclatura que antecede y continúa el nombre CI, puede ofrecer algunas dificultades para tener una visión en contextos históricos y conceptuales para quienes no han realizado estos viajes y visitado siguiendo las metáforas del autor - a los principales teóricos citados, ya sea con perspectivas cercanas u otras. Por tanto, recomendamos su lectura.

Expresa que documentación, recuperación de información, ciencia de la información son términos y expresiones que responden por la misma búsqueda: el control de la dimensión de los contenidos multiplicados o, en otras palabras, la organización del conocimiento o, aun para el humanismo, leer el libro del mundo. Algunos se toman definitivamente como sinónimos o extensiones, un resultado directo de la noción de evolución de la CI. Crítica los rasgos disciplinarios de los estudios informacionales que conducen a la institucionalización de una ciencia de la información, es decir, en una perspectiva lineal parcial/superficial de la Bibliotecología a la Bibliotecología Especializada, de esta a la Bibliografía, de esta a la Documentación, de esta a la Documentación Microfotográfica y de ahí a la CI.

Pero se detiene en Jesse Shera, quien, en los años cincuenta y sesenta:

presentará sensibilidades - fragmentos remotos de un humanismo perdidoque luego serán incorporadas directamente por la tradición pragmática: la llamada CI como ciencia social, estructurada en una filosofía de acción, enfocada al análisis de contextos — situaciones - de uso de la información; la necesidad de una hermenéutica de las prácticas informativas. Es decir, el ser humano y sus relaciones sociales como objeto de estudio de una «ciencia de la información» (1973, p. 59, traducción propia).

En las definiciones clásicas de la época posicionadas en el contexto científico, como la más citada de Borko (1968), considera la fuerte influencia de una tradición epistemológica en la Física, al afirmar que la CI representa la disciplina que investiga las propiedades y el comportamiento. En esta definición se otorga un alto grado de relevancia al análisis de los sistemas de información, la codificación de mensajes y la mirada a la eficiencia en la transmisión optimización - del desarrollo de las computadoras y la dinamización de las técnicas de programación. Se destaca la aproximación fundamental del área, 
dentro de su ámbito teórico inicial, a las ciencias puras o exactas, con la ingeniería de la información como principal horizonte de investigación.

Para agregar ideas, analiza la característica empírica de la CI, a través de algunos autores como Zunde e Gehl (1972) y, en especial, la tesis de Pinheiro (1997) comentada en una cita al pie de página (p. 62) sobre la fundamentación de la CI como ciencia social.

A continuación, plantea la perspectiva de los cognitivistas informacionales, a través de Wersig e Nevelling (1975) y uno de los más visibles exponentes, Brookes (1980) como también Belkin e Robertson (1976) (pp. 65-66) y la relación con el posicionamiento como ciencia social. Asimismo, presenta las investigaciones desde 1975 desde la URSS de Mikhailov, Chernyi e Gilyarevski (1980) y la formulación de Informatika (p. 67). En relación con el pensamiento mikhailoviano, refiere a Norman Roberts (1976), su crítica al mentalismo y la necesidad del análisis de categorías complejas como la receptividad y manipulación de información dentro de los estudios informacionales, además de versiones que toman al ser humano como mero receptor del aumento de la información. Destaca los aportes de Roberts a la preocupación por el mentalismo de los análisis del cognitivismo informacional y en el análisis a la narrativa que abre caminos para la tradición pragmática o sea el paradigma social, manifestada por Frohmann y Capurro dos décadas después. Pone especial atención a la concepción de la CI para Brookes (1980a), una ciencia social centrada en la interacción entre procesos físicos y mentales o la relación entre modalidades de pensamiento subjetivas y objetivas, en esta esfera epistémica, su principal objetivo es aprender de la investigación en contextos objetivos. La extensión de las técnicas analíticas desde las ciencias exactas a los estudios informacionales aparece irreflexivamente a los ojos de Brookes, es decir, no existe un discurso filosófico real que justifique esta trascendencia. Saldanha considera el trabajo profundo de Brookes (1980a, 1980b, 1980c, 1981) sobre los fundamentos de la CI: «como una de las narrativas más bellas de una epistemología de la imaginación» (p. 70). La narrativa brookesiana va a la problematización metafísica para intentar comprender dónde encajan los supuestos del CI en la clasificación histórica del conocimiento, buscando otro horizonte de investigación informacional objetiva e 
incorpora como compañero de viaje a Karl Popper y su obra Conocimiento objetivo. Se presenta la relación con los tres mundos de Popper y la epistemología objetiva para una fundamentación teórica de la CI. Esta debe reconocer que la información (conocimiento fragmentado) y el conocimiento (estructuras de información coherentes) no son entidades físicas, sino instancias que existen solo en espacios cognitivos (mentales) (p. 73).

Es destacable esta primera mención a la perspectiva del emblemático teórico Rafael Capurro, por tanto, nos detenemos en ella. Capurro (1991) con sus aportes:

afirma que el concepto principal en CI no es información; el concepto principal en esta área es el ser humano en su contexto. La justificación existencial de la $\mathrm{CI}$, es el intercambio de información que siempre ha ocurrido entre seres humanos. La información no es necesariamente el producto de un proceso de representación, o algo que se transporta de una mente a otra, sino que es necesariamente una dimensión existencial de nuestro ser y estar en el mundo con los demás. Reconociendo el área informacional como una disciplina argumentativo-interpretativa de la Retórica, basada en una hermenéutica de la relación entre el ser humano y la producción y registro del conocimiento, el autor formula un concepto de CI basado en la necesidad humana específica de compartir con los demás. Busca una definición armónica entre los supuestos sociales y tecnológicos del área, y no una dicotómica, limitante. Es probable que aquí se encuentre la línea más clara, sólida y directa de manifestación pragmática, definiendo un retorno de los estudios de organización del conocimiento a los estudios del humanismo, reconectando el CI con la Retórica y la Filología, recuperando implícitamente el proyecto de la epistemología social de Shera, definiendo así un circularidad en los cambios de la epistemología informacional (p. 75, traducción propia).

A continuación, regresa a Wersig (1993, pp. 230-235), que presenta los sistemas tecnológicos como organizaciones sociales y que percibe a la CI como «un prototipo de la ciencia posmoderna, como la nueva situación del conocimiento despersonalizado, con credibilidad en conocimientos y tecnologías, fragmentado y racionalizado (...), dirigido a estrategias de resolución de problemas». Asimismo profundiza sobre las concepciones de Wersig, en la línea de argumentación de Capurro (1991) y con base en Luhmann, sobre la CI preocupada por los individuos y el uso de sus conocimientos, buscando una comprensión de los actores en el proceso de transformación del conocimiento y sus acciones. Por tanto, dice Saldanha que el estudio de la comunicación ocupado en el proceso de reducción de la complejidad; construcción de modelos e interconceptos (pp. 75-76). 
Después navega entre varios autores y las diversas denominaciones de la CI, en especial en los años noventa, cuando la discusión sobre su cientificidad gana un impulso considerable [3].

El final del capítulo 5 expone la postura del autor en esta etapa:

A menudo, cuando leemos el conjunto de formulaciones provenientes de diferentes ángulos, nos perdemos tratando de identificar qué es y qué no es una 'ciencia de la información'. El pensamiento inmediatista, acrítico puede sostenerse, en este callejón sin salida, con los discursos de la interdisciplinariedad y la posmodernidad en el ámbito científico, es decir, si es tan difícil decir «esto es ciencia de la información»o «esto es ciencia», «no es ciencia de la información», es fácil concluir: este es un tema contextual; somos un área de investigación interdisciplinar y posmoderna. El pragmatismo superficial y la epistemología superficial, por la breve contextualidad verificada, sin analizar los sentimientos, ideologías y poderes involucrados en el recorrido científico corroborarían la afirmación (p. 78, traducción propia).

\section{El viaje y las narrativas críticas de la discusión sobre la terminología y su marco conceptual de la epistemología histórica de la Ciencia de la Información}

\subsection{Expresso Belo Horizonte - Copenhague. Ensaio noturno para variações dissimuladas sob-sobre um mesmo tema?}

El capítulo 6 retoma las lecturas que lo inspiraron en el lapso 2005-2008 el camino trazado por la epistemología de la imaginación de la CI, durante la maestría del autor en la UFMG, enfocado a:

la biografía de un nombre, el plano político de las justificaciones para otra demarcación en los estudios de organización del conocimiento y los márgenes de posibilidad de mil dedos apuntando hacia el horizonte prometedor del llamado 'nuevo paradigma'. Es decir, investigamos, a la luz de una historiografía también de orden filosófico pragmático, la política institucional de línea representacional dentro del CI, como en otras áreas que, con otras nomenclaturas, construyeron teorías y desarrollaron prácticas de meta-representación, expandiendo nuestra comprensión del panorama social epistemológico de los estudios de la información (p. 79, traducción propia).

Por tanto, la propuesta ya adelantada en los capítulos anteriores es analizar las narrativas de presencias y ausencias manifestadas en relatos de los mitos 
descriptivos del origen de la CI, lo que le permitirá definir la historia de su gestación y hasta dónde llegan sus fronteras. La investigación epistemológica expuesta está enfocada a problematizar la praxis de la construcción de la justificación junto al compañero de viaje, Wittgenstein, en su reflexión pragmática.

A continuación, considera la CI como nomenclatura institucionalizada y legitimada, como una categoría reciente. Pero la organización del conocimiento encaminada a la representación, transmisión y preservación tanto de la forma como del contenido y sus principales prácticas, «son actividades remotas» (p. 81). Profundizando en el pragmatismo, manifiesta que la base del análisis terminológico solo ha asumido «una filosofía representacional: pensar en el lenguaje como representacional».

En varios apartados del capítulo analiza las cartografías epistemológicas de los estudios de información con el fin de demostrar el desplazamiento a lo largo de las diferentes rutas. El análisis está precedido por comentarios sobre la política de justificación / creación / adopción del término ciencia de la información dentro de instituciones que históricamente se ocuparon de la organización del conocimiento. A este respecto, describe los reemplazos de nombres de instituciones, escuelas, instalaciones, centros de investigación en Bibliografía, Biblioteca y Documentación para la CI en Brasil a partir de 1960. Y evidencia que poco después comienzan los discursos dentro de los estudios informativos y destaca la definición de las diferencias y convergencias entre estas áreas de investigación y la propia $\mathrm{CI}$ :

y la enumeración de las llamadas 'relaciones interdisciplinarias' entre ellas, aunque vivan culturalmente al margen, en un principio, de un cambio de nomenclaturas. (...) como defienden muchos autores, la CI nace de la interdisciplinariedad lo que, política y epistemológicamente, este cambio de nombres no necesariamente revela. La imagen de la llamada 'ciencia de la información' no nace en 'neutrales', es decir, desprendida de una gramática y una tradición predefinida, pero aparece como una superposición de áreas como Documentación, Bibliografía y Bibliotecología como una intensificación de los estudios de prácticas específicas en estas áreas (...) (pp. 82-83, traducción propia).

En consecuencia, afirma que la CI no nace interdisciplinaria y «mucho menos posmoderna como algunos discursos defienden». Es «en su construcción sociopolítica, una intensificación de la especialización en el tratamiento de la 
información, una especialización de carácter tecnológico» y la interdisciplinariedad ganará más atención (p. 84). Y concluye: «La CI nació como una de las especializaciones más profundas del siglo XX».

El capítulo es muy rico en reflexiones sobre esta perspectiva, apoyándose al inicio en Puntel Mostafa (1996) y el emblemático artículo de Jesse Shera (1980) y Shera y Cleveland (1977) (pp. 86-90). Y posteriormente (pp. 93-95), entre otros, en Galvão (1993) y (Fonseca, 1979).

El eje central de la narrativa está en la crítica a:

la linealidad de bibliotecología clásica / bibliotecología especializada / documentación / ciencia de la información - dicho, en general, desde el ángulo de las instituciones: biblioteca pública / biblioteca especializada / centro de documentación / centro de análisis de información- es solo una formación discursiva de sustituciones de actividades vinculadas a la clásica biblioteconomía, en sus salas y sótanos, de sectores de la biblioteca pública que en ocasiones responden a una carencia concreta de una empresa o universidad, por ejemplo (p. 89, traducción propia).

Por otra parte, plantea la preocupación por la nomenclatura y clasificación en Brasil por los organismos y eventos nacionales sobre la disciplina o aquellos especializados en categorizar a los investigadores como también la denominación de posgrados universitarios (pp. 97-99).

Este énfasis teórico sigue siendo, revela Hjørland (2000), vía Copenhague, donde se presentaron los mismos problemas terminológicos, centrado en el enfoque particular de la aplicación de tecnologías modernas, o sea la especialización de los estudios de organización del conocimiento en el horizonte tecnológico.

En Brasil menciona, entre otros, los trabajos de Dias (2000), Ortega (2007) y Barbosa, et al. (2000), referidos a la internacionalización del nombre CI y específicamente en la UFMG.

Sobre la base de estas afirmaciones, estima la importancia de comprender con una epistemología histórica crítico-poética de Bachelard (1974) y una epistemología de la imaginación, «las sensibilidades que justifican un nuevo vocabulario y rechazar otro, y solo entonces analizar las demarcaciones que este cambio propone» (p. 104). De este modo sigue su viaje en torno al análisis de las perspectivas en Belo Horizonte y en Copenhague la mirada de Hjørland. 
Finalizando nuestra guía, aunque son diversos y significativos los aportes del capítulo, citemos un texto que sintetiza algunos conceptos:

Não há nenhum problema em alterar o nome de uma escola, de um programa de pesquisa, de uma revista científica. Não há nenhum problema em adotar um paradigma a partir de uma filosofia representacional. Como não há nenhum problema com as palavras, com os termos como "ciência da informação", "bibliografia", "documentação". Os problemas são sociais, logo, podem aparecer nas circunstâncias de justificação por nomes e escopos disciplinares. No entanto, compreender uma ciência, sua história, seu desenvolvimento, é compreender seus discursos e suas escolhas, sua paisagem social (p. 112).

\subsection{Nunca fomos interdisciplinares. A invenção neopositivista da natureza}

El autor parte en el capítulo 7 de una afirmación anterior, extensamente expuesta: la $\mathrm{CI}$ es otro nombre para la organización de los estudios del conocimiento, un antiguo estudio filosófico de la representación y, a partir de ella, continúa el recorrido «proponiendo otra mirada a la llamada interdisciplinariedad, para pensar en la unidad solidaria de la producción especializada y competente de estudios informacionales» (p. 136). Desde la epistemología de la imaginación propuesta, busca mirar críticamente el concepto de interdisciplinariedad dentro de la CI, como si fuera un fundamento específico que impulsa el área y reconoce a la interdisciplinariedad como una práctica necesaria en todos los campos del conocimiento, que siempre se ha practicado en diferentes grados. En este sentido, «La CI no es mucho más interdisciplinaria que la mayoría de las ciencias, ni tampoco su carácter»».

La propuesta del capítulo es reflexionar sobre «la reducción del aura —y no la relevancia- del término interdisciplinariedad, y transitar por el concepto como solidaridad, siguiendo a Rorty $(1997,2000)$, el encuentro de disciplinas como proceso de intercambios, encuentros y sedimentación de nuevos vocabularios» ( $\mathrm{p}$. 138, traducción propia).

Sin embargo, manifiesta que si partimos de un análisis hermenéutico-pragmático, nos damos cuenta de que, en el caso de la CI, hay una subversión del concepto de interdisciplinariedad, una especialización de la complejidad y un estrechamiento de visiones, que parten desde la emancipación de la Bibliotecología Especializada. 
Confirma nuevamente, como en anteriores narrativas, su visión:

$\mathrm{O}$ encontro, em meados do século $\mathrm{XX}$, de engenheiros, bibliotecários, linguistas, filósofos e tantos outros em torno do objeto "informação", teria dado origem a uma nova ciência, uma "ciência da informação", uma ciência reduzida a) à própria ciência - e não aos sujeitos -, legitimando o mito do cientificismo, criticado, dentre tantos, por Moles (1995) e Wittgenstein (1979); b) à tecnologia - e não ao conhecimento - legitimando o mito da tecnocracia, por tantos contestado, como por Mills (1975); c) à realidade asocial - e não à realidade das comunidades que interpretam a seu modo o mundo em que vivem -, legitimando o mito do essencialismo, des construído pelos sociólogos e antropólogos da ciência a partir da Segunda Guerra Mundial, e por toda a legião dos pragmáticos, incluindo os atores discursivos do pragmatismo informacional. A informação, quando se dá a formalização da CI. A informação, quando se dá a formalização da CI aparece substituindo o sujeito, fragmentando a ciência, separando conhecimento e sociedade, valorizando o cientificismo acima da racionalidade - esta que não ne cessariamente está nos laboratórios e salas de aula. A CI aparece como uma ciência para o Estado, para o Exército e para o Mercado, não para o indivíduo. Ou seja, uma ciência que vai contra os pressupostos sociais de uma interdisciplinaridade, uma ciência que nasce contra o interdisciplinar ( $\mathrm{p}$. 140).

De acuerdo con la metáfora inicial de Wittgenstein (1979) afirma que:

los límites de mi mundo son los límites de mi lenguaje. CI, la ciencia de las fronteras, no puede tener límites. Así, podemos señalar los entornos y hechos más diversos y decir: «Esto es ciencia de la información»; que es lo mismo que decir: «Esto no es ciencia de la información»" (p. 144, traducción propia).

Sobre la base de lo antes planteado, camina en estos textos con diferentes preguntas sobre términos, «como lo hizo Wittgenstein a lo largo de su actividad filosófica» (p. 145), pero con una respuesta clara con respecto a la visión de la CI como el área que más trabaja con el diálogo, «la solidaridad entre saberes». Y elogia el concepto solidaridad: «Estamos usando un término antiguo que nos permite mucha menos confusión, incertidumbre y fetichización como el término interdisciplinariedad» (p. 148).

Por tanto, debe centrarse más en conceptos como solidaridad y autonomía. Solidaridad que reconoce que su objeto nunca sobrevive socialmente bajo un solo método y una sola teoría. La autonomía que solo el investigador que se construye desde múltiples perspectivas, como en el universo humanista, puede sustentar la existencia de hábitos interdisciplinares.

La caminata por los textos (pp. 149-157), entre otros, de Carlos A. A. Araújo (2003), Boaventura Santos (1987), Puntel Mostafa (1986), Gómez (2001), 
Guzmán Goméz (2005), y la narrativa brookesiana (Brookes, 1980a) reafirman sus principales conceptos sobre la CI, como un incesante viaje hacia la especialización de los estudios informacionales, hacia la objetivación del conocimiento, caracterizada por un positivismo o un neopositivismo.

Finalicemos con sus palabras:

La CI —o sus otros nombres, como Bibliotecología, Documentación, Biblioteca y Ciencia de la Información- están justificados, creemos bajo una epistemología de la imaginación, no porque sea un participante activo en la sociedad de la información, o porque sea una respuesta inmediata - e inmediata - a los problemas de una «explosión de información», sino de cualquier sociedad; si es, en ciertos espíritus, interdisciplinar, es por estos perfiles de investigadores, no porque haya nacido de una esencia interdisciplinar; y la CI no es necesariamente más interdisciplinaria que otras; y, finalmente, la CI no es una ciencia porque está directamente vinculada a nuevas TIC: todas las ciencias, a lo largo del siglo XX, están conectadas a ellas, algunas mucho más que la CI, otras mucho menos (...) (p. 154 , traducción propia).

\subsection{Desusos do Messianismo do paradigma. A corrida para desinventar tradições}

El capítulo 8 discute la cuestión epistemológica de la clasificación de la CI y, específicamente, la discusión de paradigma dentro de los estudios informacionales, optando por la noción de tradiciones, como lo ha expresado anteriormente. En este sentido, se propone analizar los siguientes aspectos:

a) aprofundar as discussões sobre cientificidade em CI;

b) propor noções sobre a classificação das movimentações epistemológicas da área;

c) desvelar pontos críticos no posicionamento da CI como disciplina social e aplicada;

d) rever posicionamentos de justificação epistemológica na epistemologia informacional;

e) abrir alternativas para um criticismo informacional, na busca por compreender a epistemologia como um campo de revisões, anti-espontâneo, como nos convoca Bachelard $(1968,1974,1983)$ (p. 160).

Bajo el subtítulo «Paradigmas segundo Thomas Kuhn: em direção a Ciência da Informação», presenta estas tradiciones siguiendo los textos del físico, magister en Sociología y doctor en Ciencias Sociales Jesus de Paula Assis (Assis, 1993) en el 
marco de las ciencias sociales. También navega en las perpectivas de Eugênio, França e Perez (1996), Nehmy et al. (1996) y Oliveira (1996, 2005).

En el otro subtítulo: «Paradigmas nas Ciências Sociais e na Ciência da Informação», expone un análisis de la visión paradigmática de los textos de Kuhn y en el siguiente: «"Kuhn na Ciência da Informação: analisando as incongruências do uso", bajo "una epistemología de la imaginación y una filosofía del no, presentas algunas provocaciones o sensibilidades abiertas para una lectura alternativa de la epistemología de la CI"».

Se destacan varios puntos: a) No existen tres paradigmas, manifiesta su desacuerdo con los paradigmas defendidos por Capurro (2003) y acude a la división realizada por Rendón Rojas (1996), en la existencia de grandes teorías dentro de la epistemología de los estudios informacionales de una teoría inicial llamada sintáctica, una posterior llamada semántica, y, finalmente, un enfoque pragmático flexible (p. 174); b) la CI no persigue un paradigma «el área de los estudios informacionales no sustenta un consenso general, no puede ni debe apoyarse en un macroconsenso, la macroteoría de la información y la dispersión de corrientes demuestra la despreocupación por este ecumenis»; c) la CI no es inmadura; d) la CI no puede ser paradigmática pues su surgimiento está precedido por un momento de inseguridad profesional, esta «inseguridad» que nos habla Kuhn (1975) es una de las características fundamentales del área; e) No existe incomunicabilidad entre las principales teorías dentro de CI. Por el contrario, existe un intercambio permanente de habilidades y conocimientos.

Al referirse al punto $f$, dice:

Recuperando a última margem da metáfora acima, a CI, podemos afirmar em outra figura de linguagem, não terá momentos de paz epistemológica, o armistício hermenêutico da ciência normal - mas sempre se encontra na dança permanente das interpretações. Será - seria - necessária - e realmente possível - a condição de uma suspensão momentânea da discussão sobre os fundamentos da ciência e da teoria conjugada, como argumenta Kuhn (1975)? Por que a CI deve parar de se perguntar o que é e o que não é uma Ciência da Informação? Racionalmente, no vemos ninguna razón. Epistemológicamente, dentro de una epistemología de la acción bachelardiana, una epistemología de la imaginación, mucho menos. Exatamente por esta razão a linha de argumentação de longa duração que aqui chamamos de tradição pragmática chama atenção para uma permanente revisão das propostas teóricas e seus contextos ao longo da história da área voltada para a organização do conhecimento. Esta tradição nos chama 
atenção para o fato de que o próprioconhecimento não é um produto fechado e intocável, mas fruto de uma construçãocompartilhada de significados, cercada por imaginários que contribuem para sua presentificação no seio das sociedades (p. 177).

Después de la profundización de cada uno de estos puntos, finalmente, manifiesta: g) la CI no aparece como un área dentro de los estudios de organización del conocimiento dotada de un nuevo paradigma.

Todo el capítulo es una fuente de reflexiones que permiten acercarse a distintas perspectivas desde la mirada del autor, quien busca comprender el pragmatismo informacional desde el «retorno» a la Retórica y la Filología dentro de la organización de los estudios del conocimiento, así como la relevancia del lenguaje y la hermenéutica para la $\mathrm{CI}$, recuperados con mayor intensidad en la epistemología informacional contemporánea.

\section{La epistemología histórica de las últimas décadas: los aportes críticos para el debate de un epistemólogo anclado en el Ecce Liber}

\subsection{Fábula da criação. Uma sociedade sem informação e sua ciencia}

El capítulo 9 expresa las principales ideas del autor, por tanto, lo recomendamos para quienes prefieren conocerlas desde el inicio para comprender mejor las narraciones.

Inicia con la afirmación, en consonancia con gran parte de los especialistas del área, sobre la baja construcción epistemológica y cita a Gómez [4] (2006, p. 327) al advertir la inexistencia de un número significativo de investigaciones sobre aspectos más teóricos del área, como los relacionados con la epistemología, la elaboración de modelos y cuestiones conceptuales. Y acude, en concordancia con su pensamiento, a Puntel Mostafa (1983, p. 223): «La reflexión no puede ser un apéndice de la práctica, ya que solo se transformará cuando recupere su sentido, que es siempre una cuestión filosófica». La preocupación por la inmediatez del hacer parece haber llevado a los estudios sobre la organización del conocimiento a 
ir más allá, en numerosas investigaciones, del fundamento teórico, apegándose casi exclusivamente a un practicismo, preocupado únicamente por la aplicabilidad.

Es en la dirección opuesta a este pensamiento que el autor propone este viaje. En este contexto, «la epistemología se presenta en ocasiones, para la CI, como una isla desconocida, un territorio utópico y que no merece una exploración más profunda, dada su característica subjetiva y no inmediatista» (p. 189, traducción propia).

Bajo el subtítulo: «Onde dormem os trabalhos teóricos dentro da Ciência da Informação: uma passagem na imaginação da crítica da aplicabilidade pelo praticalismo» reconoce que «basta uma caminhada pelos becos e travessas da epistemologia» de la CI para verificar en la profusión de trabajos y debates la convergencia de teorías e indicios de meta-teorías, pero también la presencia de una tradición pragmática que responde de diferentes maneras, y «solo las epistemologías capurriana y hjørlandiana dan cuenta de una miríada de propuestas afirmativas»».

Para el pragmatismo informacional la teoría es una formulación de uso y es necesario teorizar el uso, acudir a los entornos de deliberación de uso $-\mathrm{O}$ comunión de prácticas - y describir los procesos de manipulación de los objetos de estudio.

Se menciona el enfoque sobre el pragmatismo wittgensteiniano y su tradición sobre la posibilidad de resolver problemas, como también la de Brookes (1980a) sobre que los problemas no son nuevos (pp. 190-191).

Después de citar la mirada de Mostafa (1996, p. 44): «Decir que la información es el nuevo paradigma de la sociedad del siglo XXI no nos basta en el ámbito de la información (...)» (p. 190), Saldanha es claro en sus afirmaciones:

Las disciplinas de la organización del conocimiento lo han conocido como un problema durante siglos y siglos. El problema, arcaico y fecundo, es: mantener, sistematizar, sintetizar, asegurar, interpretar, preservar y proporcionar acceso a los artefactos humanos y su contenido. El problema siempre ha existido y siempre se ha conocido, aunque puede que no se haya identificado en tal o cual contexto, con tal o cual nombre. La 'explosión de la información', la gran producción de documentos permitida por el desarrollo de técnicas de reproducción y dispersión de registros de 
conocimiento, no era un problema nuevo para las disciplinas de la información: era solo un desplazamiento del problema a otras arenas discursivas (...) (p. 190, traducción propia).

De este modo, plantea la cuestión de la epistemología de la CI: ¿Quién desarrolla la filosofía para contribuir a los juegos de comprensión del problema? y responde sobre las posibilidades que ofrece la epistemología, al revisar periódicamente las prácticas científicas y abrir horizontes con su ojo crítico y ofrecer a los investigadores «uma poesia da justificação». Mediante la investigación epistemológica se amplían para la mirada científica los espacios de duda sobre las causas y consecuencias, lo que conlleva a una amplitud ética del análisis del hacer en la ciencia. Percibe a la epistemología como la flexibilización de los sentidos, la relajación de la rigidez práctica y el cambio de tamaño desde el rigor de la cientificidad; en otras palabras, dice: «La epistemología es la apertura a la imaginación».

Lo que la epistemología -y su trabajo esencialmente teórico- pueden hacer -y hace- es concebir un lenguaje que sensibilice todos los sentidos del investigador, lo que aumenta la sensibilidad, como nos dice Rorty (1997). Al leer a los teóricos que investigan la vida cotidiana de su práctica, el científico comienza a ver, oír, sentir y oler sus propias construcciones cotidianas de una manera diferente; aquí, este científico o profesional comienza a reconocer su práctica como reflexiva, y no solo como 'productivo' (...) (p. 191, traducción propia).

Se pone en escena lo que ha dirigido la ruta de algunas de las narrativas del libro, la crítica al epistemólogo informacional que ha sometido la razón al practicismo, perpetuada por un arduo camino hacia la legitimación de la aplicabilidad. Y sintetiza su camino:

Este epistemólogo no refuta ni falsifica, sino que coloca estas dos instancias en la arena del debate. Este teórico de la información no presenta respuestas prácticas inmediatas a su pensamiento, sino que presenta prácticas de pensamiento centradas en el área, prácticas de pensamiento, resultado de las aplicaciones y sus impactos en la sociedad, que transitan por la epistemología informacional y rediseñan la forma de teorizar la CI (...) (p. 191, traducción propia).

En suma, se defiende una epistemología de la imaginación, que quite el peso de la explicación directa de los problemas prácticos, de la inferencia inmediata de posibles soluciones, que no vea en la CI solo la inmediatez de la aplicabilidad. La presencia de esta epistemología es de crucial relevancia para la investigación, ya que presenta la ligereza necesaria para la conmensurabilidad de los discursos. 
Finalmente, la epistemología en CI representa una práctica teórica fundamental en la imaginación científica, al introducir a los investigadores a diferentes visiones del mundo de sus problemas, presentando diferentes categorías de visibilidad para los mismos y permanentes problemas, «para o arcaico desafio da organização do conhecimento» (p. 192).

Es de interés el análisis y comentarios sobre los trabajos teóricos (p. 192 y ss.) en el ámbito de los estudios informacionales al considerarlos como el necesario análisis crítico y provocador del concepto de aplicabilidad en CI. «Es el análisis de lo que es la aplicabilidad aquí y allá: los matices, los horizontes, la relevancia, la aplicabilidad», en especial, «dentro de la poética de la tradición pragmática», aplicabilidad como re-contextualización, es decir, analizar el espectro del concepto de lo aplicable es encontrar preguntas sobre los contextos de delineación de usos que las teorías, métodos y productos científicos puede realizar.

Se destaca las referencias a la idea saraceviciana (Saracevic, 1996) de la participación de la CI en la sociedad de la información, la propia construcción y adopción del término ciencia de la información bajo una política que parte de una filosofía de representación. Esta afirmación está dentro del marco de:

la escasez de una epistemología provocativa y sensible, creemos, ha convertido la epistemología de los estudios de la información en una receta desde respuestas simples a problemas objetivos, una aclaración por parte de lo inmediato en un mundo que cambia rápidamente. De ahí una serie de importaciones indiscriminadas de eslóganes como «el mundo actual depende de la información», «sin información es imposible adquirir conocimiento», «la sociedad actual no vive sin tecnología de la información». Estas máximas sirven como justificaciones superficiales para introducir un objeto de investigación en una ciencia que también utiliza el término información en su nombre, a partir de la década de 1960. Sin embargo, no profundizan la relación entre los contextos ideológicos y de mercado que conducen a la dispersión de estas frases y su consiguiente vaciamiento (...) (p. 194, traducción propia).

En este sentido considera la idea, acompañada por parte de la Sociología de mediados del siglo XX, de que el área nace con la guerra (segunda guerra mundial) y la creación de varias instituciones internacionales y en Brasil, es «uma das grandes penumbras que adormecem uma epistemologia da imaginação». El área de investigación de la información se justifica epistemológicamente porque «a) está en el corazón de la sociedad de la información, b) está íntimamente 
relacionada con las tecnologías de la información $y$, finalmente, c) es esencialmente interdisciplinar» (p. 195).

La perspectiva de Saldanha sobre la sociedad de la información y las discutibles transformaciones en el mundo de la información y del conocimiento (p. 195 y en varios textos del libro) no es novedosa, pero no deja de ser pertinente en el contexto de sus abordajes, en especial, los dirigidos al área de organización del conocimiento como un campo orientado a la ingeniería del intercambio de mensajes y la disponibilidad dinámica y objetiva de representaciones. Y concluye: «Vivemos séculos e séculos produzindo e organizando 'informação', e isso não permitiu que o mundo se tornasse um mundo menos ou mais informado nem antes nem depois da institucionalização de uma ciência para a informação» (p. 196). Así, la información se convirtió en el significado de la organización del conocimiento, cuando en realidad reflejaba parte de su aplicación como rama del árbol del conocimiento (p. 197).

Un aporte significativo del capítulo es presentado a continuación (pp. 197-199), en el marco de la concepción de que la ciencia:

es una comunidad con propósito, como la asociación de vecinos, el club de fútbol y las tribus indígenas. Pero debe, dado que su misión es el conocimiento, hacer sugerencias para la solidaridad humana, no solo para la competencia. Los trabajos teóricos deben responder de forma preliminar, en cada ámbito, a esta misión. Por ello compartimos el resumen de las sensibilidades de justificación para la existencia y para la convocatoria de trabajo teórico dentro de la CI (...) (p. 197, traducción propia).

Comparte el resumen (pp. 197-199) de «las sensibilidades de justificación para la existencia y para la convocatoria de trabajo teórico dentro de la CI»:

a) en la sensibilidad de que la práctica no es más que pensamiento en acción, no es más que epistemología del espíritu complejo y poético defendido por Bachelard (1968) y se debe - al contrario de fuertes tendencias en el área- no permitir una orientación hacia el practicalismo;

b) la sensibilidad de que las prácticas deben ser criticadas no solo en su aplicabilidad mercadológica, sino también en su aplicabilidad ética, o sea, se está hablando de comprensión aplicada, de llegar a la comprensión a partir de la interpretación /representación/ comunicación de la información; 
c) la sensibilidad de que el concepto de aplicabilidad no puede colocarse en un trono intocable, especialmente en el trono del practicismo. Por el contrario, debe discutirse y entenderse. Aquí nuevamente discute los conceptos de sociedad de la información y demás términos legitimando la CI (p. 200);

d) la sensibilidad que es necesario entender la aplicabilidad en la CI en la sociedad, y esto es parte, antes, de un plano filosófico-epistemológico, que de un punto de respuesta-práctica del consencuencialismo, del practicismo.

Saldanha reitera su afirmación sobre los diferentes conceptos de CI, como el de Borko (1968) y el de Capurro (1991), y observa que las Ciencias de la Información están muy por detrás del siglo XX, pero con diferentes nomenclaturas. Existían independientemente de la sociedad de la información, la sociedad del espectáculo, la sociedad medieval, el término ciencia de la información.

Si la CI 'nace' debido a un contexto de 'explosión informativa' y al alcance de la propia gestación de una llamada sociedad de la información, cuando esta noción es primitivista, en el sentido wittgenteiniano, la expresión sociedad la información se vuelve tan común que ya no se percibe, ya no se justifica, ni por su razón práctica ni por la pretensión de significado, hablar de una "sociedad de la información". Existirá no por una demanda de la "sociedad de la información", sino por la experiencia social de construcción del conocimiento en la sociedad que lo rodea, en el tiempo que pasa, como siempre lo ha hecho (...) (p. 199, traducción propia).

e) la sensibilidad de que una filosofía, en estrecha relación con una filosofía pragmática del lenguaje, es permanentemente necesaria para la comprensión de los movimientos teóricos, terminológicos y prácticos dentro de CI.

Es destacable el cuestionamiento expuesto en las últimas páginas del capítulo (pp. 201-208) a la interdisciplinariedad como una de las principales propiedades de la CI.

Saldanha plantea, seguramente para el debate, que:

los mismos autores que parecen coincidir en que el CI nació interdisciplinaria también comparten la idea de que nació bajo la influencia de un pensamiento fisicalista, o de un paradigma físico (Capurro, 2003), o de una teoría sintáctica. (Rendón Rojas, 1996) —en nuestro vocabulario, desde un punto de vista filosófico representacionalista. Este doble acuerdo se produce porque los epistemólogos, teóricos e investigadores que utilizan uno u otro de los enunciados- CI nació interdisciplinaria, CI nació bajo un enfoque fisicalista, consideran que su surgimiento tiene lugar en el contexto de la posguerra mundial. $\mathrm{Y}$ este es precisamente el contexto en el que, dentro del ámbito de la organización del conocimiento, el pensamiento fisicalista ejerce 
una influencia directa sobre el ámbito, delimitado por una perspectiva positivista $\mathrm{y}$, en determinadas perspectivas, una lógica positivista (...) (p. 202 , traducción propia).

Asimismo, como lo afirmó en capítulos anteriores, ubica a Saracevic $(1996,1999)$ como «principal fuente de esta reflexión problemática» y acuerda con otros epistemólogos que esta área parte de la recuperación de la información basada en la profundización de la lógica formal, uno de los enfoques contra los que se inicia el movimiento interdisciplinario (Saracevic, 1999).

Pero el autor prefiere alejarse de la discusión sobre una cierta «interdisciplinariedad» del área, y apunta el argumento en la fragilidad sobre la que descansa esta justificación epistémica de la CI. Y profundiza en la línea anteriormente expresada:

Estos mismos autores que no se dan cuenta de la paradoja de afirmar que CI nace simultáneamente positivista e «interdisciplinar por naturaleza» también recuerdan que el área carece de una plataforma epistemológica en sus primeros días, así como en los días actuales. Son estos autores quienes nos advierten que la zona sufre una discusión epistemológica profunda, y que CI nació carente de ella, dependiente de una mirada unilateral a la tecnología (...). Esta es la historiografía que presentan, entre muchos, autores como Capurro $(1991,2003)$ y Saracevic (1996), la historiografía que, en general, percibe el surgimiento del área a partir de la aparición de la noción de información dentro de los estudios de organización del conocimiento e institucionalización de la expresión 'ciencia de la información'(...) (p. 203, traducción propia).

En este sentido, apunta a la depreciación del positivismo en las ciencias humanas y un desperdicio teórico, que Durkheim y Comte estaban «equivocados», muchos de los llamados espíritus positivistas, como Paul Otlet y Euclides da Cunha, realizaron trabajos mucho más «complejos» que ciertos proyectos o ciencias que se pretenden o justifican como interdisciplinares y transdisciplinares. Considera que a la CI le preocupa más el «complejo» de ser «ciencia inmadura» y “este complejo de «ciência em vías de acontecer», por ejemplo, denunciado por Brookes (1980a), Goffman (1975) y Frohmann (1992). En esta medida, la noción de interdisciplinariedad aparece como una herramienta política, antes que un concepto epistemológico (...)."

Y considera, invocando a Gomes (2001), si no sería importante para la CI preguntarse quién de sus espíritus realmente llevan a cabo proyectos interdisciplinarios (p. 204). 
Y reafirma su postura:

Preocuparse por las demarcaciones interdisciplinarias parece una contradicción con la idea misma de interdisciplinariedad. Creemos que es más importante estudiar el espíritu que traspasa las fronteras de cualquier campo y no los límites del área, estos a menudo se vacían de significado debido a la falta de grandes espíritus científicos en sus márgenes, como Leibniz (Gusdorf, 1995) y Paul Otlet (Ortega, 2007). Si estamos tan centrados en las fronteras, parece que no nos preocupamos de realizar proyectos interdisciplinares, solo identificar y establecer los marcos de las relaciones (...) (p. 205)

En las últimas páginas (pp. 206-208) refiere a la inmediatez a la que nos conduce el paradigma y llama nuestra atención por la camisa de fuerza de la idea de interdisciplinariedad en la historiografía de la CI y afirma sobre la CI:

Aparece como una ciencia para el Estado, para el Ejército y para el Mercado, no para el individuo. Es decir, una ciencia que va en contra de los presupuestos sociales de una interdisciplinariedad, una ciencia que nace contra lo interdisciplinario (...) (p. 206, traducción propia).

Finalmente, después de invocar a Ingwersen (1996), Frohmann (1992) y Brier (1996), es relevante transcribir algunas afirmaciones, que seguramente como otras son provocativas para el debate:

Así, CI 'nace' negando la esfera comunicacional de los estudios de organización del conocimiento, identificados, en nuestro viaje, por la línea discursiva de un pragmatismo intrínseco, existente, por ejemplo, en la biblioteconomía clásica y en la Bibliografía Textual y Epistemología Social, contemporánea a esta discusión (...). CI no es una 'ciencia de la sociedad de la información'. Si esta declaración significara de lo contrario, sería una ciencia provisional, que estaría condenada a desaparecer cuando esta 'sociedad' entró en decadencia. Sabemos, en primer lugar, que el concepto de 'sociedad de la información' también es bastante frágil. La CI es una ciencia de cualquier sociedad, porque forma parte de una larga tradición de los estudios de organización del conocimiento, por lo tanto, no es una nueva ciencia de siglo XX (...). Se necesita una línea discursiva que nos haga conscientes de una CI sin información. Se necesita una historia que nos recuerde que lo que sostiene el área no es la tecnología, porque sin ella se pueden aplicar, desarrollar y difundir innumerables teorías de la CI a otros campos. La tecnología es solo una cuestión importante de investigación y aplicación en el área, como tantas otras, afirmar esto se trata, una vez más, de simplificar la historia de los estudios de organización del conocimiento. Finalmente, se necesita una narrativa que niegue la información, sin eliminarla; que niega la interdisciplinariedad, para que sea reinterpretada - se necesita una 'filosofía del no' en nuestra epistemología. Finalmente: una narrativa que nos haga conscientes de la idea de que la historia de la CI no es la historia de la información; pero ese, entre los capítulos de su biografía, está la historia del hechizo que provocó la información en el siglo XX (pp. 207-208, traducción propia). 


\subsection{El viraje lingüístico y la epistemología histórica de la ci en la última década}

El título identifica el enfoque del capítulo: «Ipásia resiste. Advinda da retórica e da filología», en especial su anclaje en la reorientación de la epistemología de la CI en las últimas décadas para una meta-reflexión enfocada en el lenguaje.

Menciona el concepto de viraje lingüístico de Habermas (2004) sobre el cambio filosófico extendido a través de disciplinas que van desde la Psicología hasta la Economía, pasando también por las ciencias exactas; una epistemología que tiene en el lenguaje su punto de partida y su punto final; «el lenguaje se toma como un objeto, como una piedra de toque para comprender la realidad, ya sea que se inserte en un discurso mentalista o fisicalista».

Este cambio epistemológico representa para Habermas (2004) el paso de las filosofías de la conciencia a las filosofías del lenguaje (p. 209). Y la reconocida teórica de Brasil González de Gómez (1993, p. 220), cita el autor, demuestra los caminos históricos de este pasaje, que trasciende los momentos ontológicos y gnoseológicos, llegando incluso a la orientación pragmática.

Así, afirma: «Neste itinerário, a partir da virada do século XIX para o XX, o signo é menos referenciado pelo seu 'papel coadjuvante de instrumento', e mais pelo seu papel nuclear de objeto do conhecimento, chegando à condição de objeto por excelencia (...). Trata-se de um regime epistemológico fundamentalmente antiessencialista e antimetafísico» (p. 209)

Este viraje se tradujo fundamentalmente en la filosofía pragmatista dentro del hacer y la reflexión sobre la información, reconocido por Capurro como paradigma hermenéutico-retórico (1992) y paradigma social (2003), Rendón Rojas (1996) como enfoque pragmático, Araújo (2003) como abordajes microsociológicos, y González de Gómez (1996a) como abordajes comunicacionales. «Estos movimientos tendrán implicaciones decisivas para los estudios de la organización del conocimiento» (p. 210) y el viraje demarcará el pasaje a la Filosofía informacional del lenguaje.

Por otra parte, en Rendón Rojas (1997), el campo bibliotecario-informacional: 
está guiado por signos articulados lingüísticamente, más allá de meros objetos sensibles a la percepción humana. De esta forma, el contexto de presentación y circulación de la información presentará al campo un enfoque pragmático que no puede pasarse por alto en los estudios informativos.

Con respecto a este giro, también acude a la mirada de Capurro (1992):

propuesta por los trabajos de Norman Roberts y Gernot Wersig, entre otros, de la década de los ochenta. Roberts buscando una aproximación al 'hombre informacional', Wersig considerando los 'actores' dentro de 'situaciones problemáticas' (...). El tratamiento racional-cognitivo de los problemas constituye para Wersig sólo un aspecto del problema del racionalismo. El llamado "hombre informativo" no puede separarse de las situaciones específicas en las que está posicionado pragmática / socialmente. Así, el individuo que vive con la información y la estructura cognitiva capaz de procesar información no pueden separarse de aspectos inherentes a la realidad social como la ética. En este entendimiento, Roberts y Wersig conducen la epistemología informacional hacia un pensamiento hermenéutico-retórico, basado en un punto de vista pragmático (pp. 2102011, traducción propia).

Según el autor, a través de una epistemología histórica, tal giro no existe. «Es, de hecho, desde Emanuele Tesauro, la marca de constitución diacrónica del campo». Por el contrario, Saldanha defiende una posición filosófica, cercana a Habermas y Rorty, que permita un retorno de los saberes tratados históricamente como humanidades, y en este sentido afirma un deseable:

rápido proceso de relativización del conocimiento, junto con la reducción de la idea de fundamentos científicos como doctrinas. Lo absoluto da paso a lo contextual en este otro régimen epistemológico, y la producción de ciencia se legitima desde el tejido colectivo de los discursos, y no desde la definición a priori de las verdades. En esta medida, el texto, entendido como el proceso cultural de la discursividad, se convierte en la manifestación del conocimiento construido de manera abierta y deliberativa (...) (p. 211, traducción propia).

A continuación, acorde al título del capítulo, refiere a las propuestas para el nuevo milenio de Ítalo Calvino como ejemplo de las posibilidades de integración de las Humanidades a los demás saberes (pp. 212-214). Alude a los significados del humanismo según Heidegger (2008), Peter Burke (2003) y Nepomuceno (2005), y especialmente en el contexto contemporáneo a Boaventura Santos (1987), quien revaloriza los estudios humanísticos y la preocupación de los humanistas por el lenguaje y en su cambio radical.

La discusión del giro lingüístico a partir de los años ochenta en Brasil es abordada en este capítulo (pp. 215-217), se presentan los principales discursos y la 
influencia de la teoría de acción comunicativa de Habermas (2004), concluyendo sobre la aproximación del actor habermasiano al lector de Calvino.

El final del capítulo, en primer lugar (pp. 218-220), está centrado en el pragmatismo, la percepción por Capurro (2003) y Rendón Rojas (1996), y en particular el abordaje del neopragmatista estadounidense Richard Rorty (1997), destacando su anti-representacionismo o insistencia en la noción de que no hay una determinación en la cuestión del estudio del conocimiento y sus relaciones. Y cita alguno de sus textos (pp. 218-219):

De um ponto de vista pragmático, a racionalidade não é o exercício de alguma faculdade chamada "razão" - uma faculdade que apresenta alguma relação determinada com a realidade. Nem é o uso de um método. Ela é simplesmente uma questão de estar aberto e curioso, bem como deconfiar antes na persuasão do que na força (Rorty, 1997, p. 87).

(...) diferença sentida entre objetos concretos e flexíveis, o pragmático diz que a diferença é apenas entre as regras de uma instituição (a química) e aquelas de uma outra (a crítica literária) (Rorty, 1997, p. 118).

(...)Todo objeto científico é uma narrativa científica divulgada na forma de uma descrição (Rorty, 1994, p. 19).

(...) Assim, “filosofia e crítica literária (...) não são coisas que devem ser separadas" (Rorty, 1997, p. 127).

En suma, concluye: el pragmático norteamericano propone un giro lingüístico radical planteando que, una vez reconocido el mundo plural del lenguaje, es decir, una vez dentro de Ipásia, su salida solo puede producirse a través del lenguaje, única forma de reconocer la idea de humano (p. 219, traducción propia).

Después de recordar el enfoque pragmático de Rendón Rojas (1996) como base esencial del estudio de la información, al reconocer la dialéctica del sujeto con el mundo circundante, y el concordante de González de Gómez (1996a) quien observa que la pragmática presenta elementos para superar los límites, simplificaciones y exclusiones de las teorías sintácticas y semánticas de la información (p. 219), concluye:

Dentro do pragmatismo, os problemas informacionais são tratados como 'questões humanas', não como demandas físicas, isto é, os problemas de classificação e catalogação não são situações complexas de livros, documentos ou bits, mas entraves/desafios da representação, da organização e da sistematização de culturas, fontes de investigação do conteúdo. Desta forma, a partir da pragmática, não são o livro nem o computador os objetos de estudo da CI, mas, sim, o mundo do saberes construído pelo ser humano, do qual estes e tantos outros artefatos fazem parte (...) (pp. 219-220). 
As filosofias da linguagem permitiriam abandonar o 'círculo improcedente entre os pensamentos metafísico e antimetafísico', ou 'idealismo' e 'materialismo', recuperando problemas históricos da filosofia que a metafísica não podia solucionar. Esta travessia da filosofia analisada por Habermas (2003, 2004), é tomada por Rorty (1994, p. 94) como a tentativa de substituição da noção de crenças verdadeiras tomadas como representação das coisas pela coerência da noção de crenças como 'regras auspiciosas de ação' (p. 220)

En segundo lugar, al final del capítulo (pp. 221-222) refiere a otros abordajes que revelan una aproximación entre la CI y Humanidades: el análisis del dominio (Hjørland; Albrechtsen, 1995) y la cibersemiótica (Brier, 1996). En este sentido, afirma:

Assim, verifica-se uma aproximação, como é tendência no ponto de vista pragmatista da realidade, entre os estudos literários e os discursos científicos: são, todos eles, elementos cercados por ideologias e utopias, por instituições e suas regras. No vocabulário da Retórica, a qual a 'análise do domínio' e a 'cibersemiótica' se integra, são todos eles discursos a serem desconstruídos. A linguagem é um objeto preliminar de estudo. Por isto, todo o conhecimento é, antes, um complexo de discursos compartilhados. Em outras palavras, todas as formas de conhecimento são narrativas sob a sombra de uma cultura específica. Da organização do conhecimento passamos a perceber a prática informacional a partir de micro-estudos, que envolvem agora os atos discursivos. Chegamos, pois, às políticas de informação (González de Gómez, 1996b), orientadas para localidades contextualizadas. Aquí em Ipásia a linguagem é processo e produto e a informação não está dada, muito menos estão suas posibilidades de organização contituídas previamente. Ipásia é o acontecimento do discurso por vir e sua ordem a ser informacionalmente negociada (p. 222)

\subsection{Estas (outras) histórias. Travessias}

En este último capítulo el autor especifica cuáles son las más irritantes afirmaciones de la construcción epistemológica e historiográfica «de algo llamado» CI:

a) El discurso que indica que estamos ante una ciencia nueva: «La ciencia de la información es una ciencia nueva»;

b) El enunciado equívoco y neopositivista (por contradictorio que sea a la filosofía analítica la oración anterior) de que «el objeto de la ciencia de la información es la información»;

c) La declaración epistémica de que existe un «carácter interdisciplinario en la constitución de las Ciencias de la Información»;

d) El fragmento neoliberal que reproduce la máxima de que somos una «ciencia para la sociedad de la información» (pp. 223-224, traducción propia). 
Este cierre del libro reafirma la crítica a la CI que establece una lista de teorías generales, tratando de abarcar todo y la totalidad del campo. Así, menciona entre ellas la cibersemiótica, el análisis del dominio, la antropología de la información, la desclasificación, la polirepresentación y neodocumentación. «Todas igualmente importantes junto de tantas outras, todas incapazes de fotografar a realidade ambulante, na esquina presente, na esquina já fugidia; todas distantes da construção secular e lenta, liberal e crítica, histórica e diacrônica, do campo» (p. 224).

Asimismo, expresa sus mayores preocupaciones de la epistemología histórica:

Una impresionante ausencia de perspectivismo para documentarse: la intensa producción de conocimientos, teorías, conceptos, métodos en el campo en los dos últimos siglos; otra amnesia impresionante predispuesta a negar la próxima producción, a ocultar las epistemologías horizontales e inaugurar siempre la rotura frágil, que suele surgir de un simulacro técnico (...). (p. 224, traducción propia).

Y finaliza con palabras consistentes con el viaje y las narrativas del libro: Nuestro objeto sigue ahí, como en la profecía Mallarmaica, como en Rosa (2001, p. 272), Un libro, uno solo. Supongo que es poesía. Será el Libro. No puedo leerlo. Ecce Liber [5].

\section{Breve reseña de los «Prefacio» $\mathrm{y}$ «Posfacio»}

Ambos, iniciando y terminando: «Prefacio» de Vinicios Souza de Menezes (pp. 18-25) y «Posfacio» de Franciéle Carneiro Garcês da Silva (pp. 240-250) son simbólicos de la voluntad integradora de los sectores excluidos por la disciplina y las profesiones del campo, desprovistos de retórica e historia. Con una perspectiva de la filosofía del lenguaje, por un lado, el prefacio, desde la filosofía amerindia de la información, y por otro el posfacio, desde la biblioteconomía negra.

\section{A manera de cierre de la reseña}

El arcoíris de ideas y reflexiones ha sido un gran desafío y debo mencionar que no me arrepiento de este arduo trabajo, quizá uno de los más complejos que he tenido que abordar. Sin duda, implicó un tiempo que debí usar para escribir con base a mis últimas investigaciones, o sea, lo que se espera en el mundo académico de 
evaluadores. De ahí que pedimos, por un lado, disculpas por posibles errores y omisiones, pero no podemos seguir profundizando y revisando por razones de tiempo, y por otro, recomendar la lectura del libro y hacer el viaje al que invita el autor en las narraciones de los valiosos y diversos aportes sobre la epistemología histórica de la Ciencia de la Información, ofreciendo nuevos (o ¿viejos?) enfoques de las corrientes teóricas. Por otra parte, debo sugerir su lectura a los especialistas en Bibliografía y Documentación e invitar al debate a los epistemólogos de CI sobre algunos paradigmas o perspectivas o, como le denomina Saldanha, tradiciones, sobre la relación de la CI, entre otros, con la filosofía del lenguaje, con la retórica y la lógica, con la dimensión estética, y en especial los procesos de construcción y desconstrucción. Finalmente, enfatizar la invalorable presentación del estimado y emblemático Dr. Rafael Capurro, un muy valioso inicio de la lectura del libro. Gracias Dr. Capurro.

\section{Notas}

[1] Saldanha, Gustavo Silva. Ciência da Informação: crítica epistemológica e historiográfica. (2020). Rio de Janeiro: Instituto Brasileiro de Informação em Ciência e Tecnologia. IBICT, 2020. ISBN 978-65-89167-01-3

[2] Invitamos a leer estas ideas profundizadas en el capítulo 10 (p.41).

[3] Invitamos a consultar pp. 76-77.

[4] Las referencias de todo el libro se encuentran al final del capítulo 11, pp. 224238.

[5] Como se indicó a lo largo de la reseña las referencias de todo el libro están a continuación: pp. 224-238.

\section{Notas del editor}

El responsable por la publicación del presente manuscrito es Mario Barité.

Nota: La corrección de estilo del presente texto fue realizada por Elena Ponte en el marco del convenio celebrado entre la FHCE (Tecnicatura Universitaria en 
Corrección de Estilo-Facultad de Humanidades y Ciencias de la Educación) y la FIC (Facultad de Información y Comunicación).

\section{Nota de contribución autoral}

La presente reseña fue elaborada únicamente por la autora. 